\title{
Age cutoff for Epstein-Barr virus-positive diffuse large B-cell lymphoma-is it necessary?
}

Chi Young Ok ${ }^{1}$, Qing Ye ${ }^{1}$, Ling Li ${ }^{1}$, Ganiraju C. Manyam², Lijuan Deng ${ }^{1}$, Rashmi R. Goswami $^{1}$, Xiaoxiao Wang ${ }^{1}$, Santiago Montes-Moreno ${ }^{3}$, Carlo Visco ${ }^{4}$, Alexandar Tzankov', Karen Dybkaer6, Li Zhang', Jeremy Abramson', Aliyah R. Sohani7, April Chiu $^{8}$, Attilio Orazi ${ }^{9}$, Youli Zu ${ }^{10}$, Govind Bhagat ${ }^{11}$, Kristy L. Richards ${ }^{12}$, Eric D. Hsi ${ }^{13}$, William W.L. Choi ${ }^{14}$, J. Han van Krieken ${ }^{15}$, Jooryung Huh ${ }^{16}$, Maurilio Ponzoni ${ }^{17}$, Andrés J.M. Ferreri ${ }^{17}$, Shanxiang Zhang ${ }^{18}$, Ben M. Parsons ${ }^{19}$, Mina $X u^{20}$, Michael B. Møller ${ }^{21}$, Jane N. Winter ${ }^{22}$, Miguel A. Piris ${ }^{3}$, Zijun Y. Xu-Monette ${ }^{1}$, L. Jeffrey Medeiros $^{1}$ and Ken H. Young ${ }^{1,23}$

${ }^{1}$ Department of Hematopathology, The University of Texas MD Anderson Cancer Center, Houston, Texas, USA

2 Department of Bioinformatics and Computational Biology, The University of Texas MD Anderson Cancer Center, Houston, Texas, USA

${ }^{3}$ Hospital Universitario Marques de Valdecilla, Santander, Spain

${ }^{4}$ San Bortolo Hospital, Vicenza, Italy

${ }^{5}$ University Hospital, Basel, Switzerland

${ }^{6}$ Aalborg University Hospital, Aalborg, Denmark

${ }^{7}$ Massachusetts General Hospital and Harvard Medical School, Boston, MA, USA

${ }^{8}$ Memorial Sloan-Kettering Cancer Center, New York, New York, USA

${ }^{9}$ Weill Medical College of Cornell University, New York, New York, USA

${ }^{10}$ Houston Methodist Hospital, Houston, Texas, USA

${ }^{11}$ Columbia University Medical Center and New York Presbyterian Hospital, New York, New York, USA

12 University of North Carolina School of Medicine, Chapel Hill, North Carolina, USA

${ }^{13}$ Cleveland Clinic, Cleveland, Ohio, USA

${ }^{14}$ University of Hong Kong, Li Ka Shing Faculty of Medicine, Hong Kong, China

${ }^{15}$ Radboud University, Nijmegen Medical Centre, Nijmegen, the Netherlands

${ }^{16}$ Asan Medical Center, Ulsan University College of Medicine, Seoul, Korea

17 San Raffaele H. Scientific Institute, Milan, Italy

${ }^{18}$ Indiana University School of Medicine, Indianapolis, Indiana, USA

${ }^{19}$ Gundersen Lutheran Health System, La Crosse, Wisconsin, USA

20 Yale University, School of Medicine, New Haven, CT, USA

${ }^{21}$ Odense University Hospital, Odense, Denmark

22 Feinberg School of Medicine, Northwestern University, Chicago, Illinois, USA

${ }^{23}$ The University of Texas School of Medicine, Graduate School of Biomedical Sciences, Houston, Texas, USA

Correspondence to: Ken H. Young, email: khyoung@mdanderson.org

Keywords: EBV, DLBCL, elderly, gene expression profiling

Received: April 21, $2015 \quad$ Accepted: May 12, $2015 \quad$ Published: May 29, 2015

This is an open-access article distributed under the terms of the Creative Commons Attribution License, which permits unrestricted use, distribution, and reproduction in any medium, provided the original author and source are credited.

\section{ABSTRACT}

Epstein-Barr virus-positive diffuse large B-cell lymphoma of the elderly (EBV+ DLBCL-e) is a molecularly distinct variant of $D L B C L$, characterized by a monoclonal B-cell proliferation that occurs in patients $>50$ years of age without a history or clinicopathologic evidence of immunodeficiency. However, patients with EBV+ DLBCL younger than 50-years-old also exist in Western countries. We evaluated the 
clinicopathologic, immunophenotypic and genetic features in Cacausian patients with EBV+ DLBCL who are $\leq 50$ years of age and compared this patient group to patients who are $>\mathbf{5 0}$ years. In patients who are $\leq \mathbf{5 0}$ years, less frequent expression of BCL6 and a trend of more frequent expression of CD30 and pSTAT3 were found in patients with EBV+ DLBCL. In patients who are > 50 years, common expression of CD30, p50, pSTAT3 and less frequent expression of BCL6 were observed. Older patients also more commonly had a poor performance status (ECOG $\geq 2$ ). Comparing EBV+ DLBCL patients in $\leq \mathbf{5 0}$ years versus $>\mathbf{5 0}$ years, both groups had similar clinicopathologic, immunophenotypic and genetic features. Gene expression profiling, microRNA profiling and treatment outcome of the younger patients with EBV+ DLBCL was not distinctive from tumors in older patients. Based on our data, we suggest that the arbitrary age cutoff for EBV+ DLBCL is unnecessary and should be eliminated in the WHO lymphoma classification scheme.

\section{INTRODUCTION}

Epstein-Barr virus (EBV) positive diffuse large B-cell lymphoma of the elderly (EBV+ DLBCL-e) is a monoclonal B-cell lymphoid proliferation that occurs in patients $>50$ years without evidence of immunodeficiency or a history of lymphoma [1]. EBV+ DLBCL-e constitutes $8-10 \%$ and $2-5 \%$ of DLBCL in Asian countries and Western countries, respectively [2-5]. EBV+ DLBCL-e is a molecularly distinct entity characterized by enhanced activity of the NF- $\mathrm{KB}$, signal transducer and activator of transcription 3 (STAT3), MEK/ERK and phosphoinositide 3-kinase (PI3K)/Akt pathways, mostly induced by EBV products [6]. In the era of treatment with cyclophosphamide, doxorubicin, vincristine and prednisone (CHOP), patients with EBV+ DLBCL-e were thought to be an aggressive variant of DLBCL. With the current therapeutic regimen, $\mathrm{CHOP}$ plus rituximab (R-CHOP), EBV+DLBCL does not confer a worse prognosis in Western patients $[5,7]$. However, the data is controversial in Asian patients $[8,9]$.

The median age of patients with EBV+ DLBCL-e is 71 years and the prevalence of EBV positivity in DLBCL increases with age, as high as $30 \%$ in patients $>90$ years [10]. The current World Health Organization (WHO) classification sets an arbitrary age cutoff of 50 years as a defining feature of EBV+ DLBCL-e. However, well-documented cases of DLBCL with EBV infection in apparently immunocompetent young adults or even in children have been reported, questioning the rationale of the current age cutoff [11-13]. To the best of our knowledge, Hong et al has been the only group of investigators who systematically compared EBV positivity in young ( $\leq 50$ years) versus old ( $>50$ years) patients with DLBCL [12]. EBV infection was less common in younger compared with older patients $(6.7 \% v s .9 .3 \%)$. In younger, patients with EBV+ DLBCL did not have distinct clinical features or worse outcome compared with patients with
EBV-negative DLBCL. In the elderly group, however, EBV positivity was correlated with advanced stage, high IPI risk group (age-adjusted), and involvement of $\geq 2$ extranodal sites. The older patients with EBV+ DLBCL also showed shorter overall survival and progression-free survival compared with young patients. These authors also showed that EBV positivity was an independent risk factor for overall survival in R-CHOP treated elderly patients. In aggregate, the data presented by Hong et al appears to support the age cutoff in the WHO classification.

In this study, our aim was to further compare clinicopathologic, immunophenotypic, and molecular findings of young ( $\leq 50$ years) versus older ( $>50$ years) patients with EBV+ DLBCL.

\section{RESULTS}

EBV infection occurs in all age groups and similar morphologic variants observed between both younger and elderly groups

A total of 46 cases of EBV+ DLBCL were identified. The number of EBV+ DLBCL patients in different age group is shown in Figure 1A. There were $16(35 \%)$ and $30(65 \%)$ patients in the younger ( $\leq 50$ years) and older ( $>50$ years) group, respectively. Similar morphologic variants were seen in the younger ( $\leq 50$ years) and older ( $>50$ years) group (Figure 1B). The monomorphic subtype is featured by monotonous sheets of large transformed B cells. The polymorphic DLBCL-like subtype shows canonical large B-cell neoplasm morphology, with a high density of large neoplastic cells and scattered cells with (Reed-Sternberg) RS-like and Hodgkin-like features. The polymorphic HL-like subtype displays a lower density of neoplastic cells with RS-like and Hodgkin-like features. The polymorphic LPD-like subtype is a DLBCL with 
Table 1: Clinical, immunophenotypic and genetic features of EBV+DLBCL and EBV- DLBCL.

\begin{tabular}{|c|c|c|c|c|c|c|c|c|c|}
\hline & \multicolumn{3}{|c|}{ All patients } & \multicolumn{3}{|c|}{$\leq 50$ years } & \multicolumn{3}{|c|}{$>50$ years } \\
\hline & $n=46$ & $n=533$ & & $\mathrm{n}=16$ & $n=104$ & & $\mathrm{n}=30$ & $n=429$ & \\
\hline & $\begin{array}{c}\text { EBV+ } \\
\text { DLBCL }\end{array}$ & $\begin{array}{c}\text { EBV- } \\
\text { DLBCL }\end{array}$ & $\mathrm{P}$ value & $\begin{array}{c}\text { EBV+ } \\
\text { DLBCL }\end{array}$ & $\begin{array}{c}\text { EBV- } \\
\text { DLBCL }\end{array}$ & $P$ value & $\begin{array}{c}\text { EBV+ } \\
\text { DLBCL }\end{array}$ & $\begin{array}{c}\text { EBV- } \\
\text { DLBCL }\end{array}$ & $P$ value \\
\hline $\begin{array}{l}\text { Median age, years } \\
\text { (range) }\end{array}$ & $61(21-86)$ & $63(16-92)$ & 0.1481 & $43(21-50)$ & $42(16-50)$ & 0.8161 & $66(53-86)$ & $51(67-92)$ & 0.6916 \\
\hline Men:women & $25: 21$ & $306: 227$ & 0.7567 & $7: 9$ & $69: 35$ & 0.1581 & $18: 12$ & $237: 192$ & 0.7054 \\
\hline B symptoms & $16(38 \%)$ & $154(33 \%)$ & 0.4981 & $7(47 \%)$ & $29(31 \%)$ & 0.2248 & $9(33 \%)$ & $125(33 \%)$ & 1 \\
\hline LDH elevation & $31(70 \%)$ & $304(63 \%)$ & 0.4133 & $12(75 \%)$ & $65(69 \%)$ & 0.5458 & $19(68 \%)$ & $239(62 \%)$ & 0.5525 \\
\hline Stage III/IV & $28(62 \%)$ & $266(52 \%)$ & 0.2133 & $9(56 \%)$ & $50(51 \%)$ & 0.5869 & $19(66 \%)$ & $216(52 \%)$ & 0.1807 \\
\hline $\mathrm{ECOG} \geq 2$ & $11(27 \%)$ & $72(16 \%)$ & 0.0783 & $2(13 \%)$ & $11(13 \%)$ & 1 & $9(36 \%)$ & $61(16 \%)$ & 0.0251 \\
\hline IPI $>2$ & $16(38 \%)$ & $221(42 \%)$ & 0.6295 & $2(13 \%)$ & $33(33 \%)$ & 0.2204 & $14(52 \%)$ & $188(45 \%)$ & 0.5506 \\
\hline$\geq 2 \mathrm{EN}$ involvement & $9(20 \%)$ & $114(22 \%)$ & 0.8522 & $3(19 \%)$ & $30(30 \%)$ & 0.5491 & $6(21 \%)$ & $84(20 \%)$ & 0.8139 \\
\hline Size $\geq 6 \mathrm{~cm}$ & $12(36 \%)$ & $130(33 \%)$ & 0.7006 & $5(38 \%)$ & $25(33 \%)$ & 0.7447 & $7(35 \%)$ & $105(32 \%)$ & 0.8086 \\
\hline CR/PR & $39(89 \%)$ & $471(88 \%)$ & 1 & $12(86 \%)$ & $93(89 \%)$ & 0.637 & $27(90 \%)$ & $378(88 \%)$ & 1 \\
\hline GCB phenotype & $14(42 \%)$ & $280(54 \%)$ & 0.2806 & $5(45 \%)$ & $69(68 \%)$ & 0.1793 & $9(41 \%)$ & $211(50 \%)$ & 0.5131 \\
\hline ABC phenotype & $19(58 \%)$ & $243(46 \%)$ & & $6(55 \%)$ & $32(32 \%)$ & & $13(59 \%)$ & $211(50 \%)$ & \\
\hline CD30 expression & $16(44 \%)$ & $66(14 \%)$ & $<0.001$ & $6(43 \%)$ & $16(18 \%)$ & 0.0727 & $10(45 \%)$ & $50(14 \%)$ & 0.0005 \\
\hline p50 expression & $14(61 \%)$ & $150(34 \%)$ & 0.0124 & $3(43 \%)$ & $32(37 \%)$ & 1 & $11(69 \%)$ & $118(33 \%)$ & 0.0056 \\
\hline p65 expression & $3(11 \%)$ & $92(20 \%)$ & 0.3252 & $0(0 \%)$ & $24(28 \%)$ & 0.1849 & $3(15 \%)$ & $68(18 \%)$ & 1 \\
\hline c-Rel expression & $5(23 \%)$ & $103(23 \%)$ & 1 & $1(14 \%)$ & $16(19 \%)$ & 1 & $4(27 \%)$ & $87(24 \%)$ & 0.7673 \\
\hline pSTAT3 expression & $9(39 \%)$ & $65(16 \%)$ & 0.0079 & $3(43 \%)$ & $11(14 \%)$ & 0.0818 & $6(38 \%)$ & $54(16 \%)$ & 0.0389 \\
\hline BCL2 expression & $12(41 \%)$ & $225(49 \%)$ & 0.4485 & $3(38 \%)$ & $33(37 \%)$ & 1 & $9(43 \%)$ & $192(52 \%)$ & 0.5024 \\
\hline BCL6 expression & $14(50 \%)$ & $417(82 \%)$ & 0.0002 & $3(38 \%)$ & $76(80 \%)$ & 0.016 & $11(52 \%)$ & $241(82 \%)$ & 0.0024 \\
\hline p53 expression & $10(43 \%)$ & $163(36 \%)$ & 0.5112 & $2(29 \%)$ & $31(36 \%)$ & 1 & $8(39 \%)$ & $132(36 \%)$ & 0.8072 \\
\hline MYC expression & $17(61 \%)$ & $293(64 \%)$ & 0.6913 & $3(43 \%)$ & $47(54 \%)$ & 0.702 & $14(67 \%)$ & $246(66 \%)$ & 1 \\
\hline MYC/BCL2 expression & $8(29 \%)$ & $152(34 \%)$ & 0.6823 & $1(14 \%)$ & $21(24 \%)$ & 1 & $7(33 \%)$ & $131(36 \%)$ & 1 \\
\hline$B C L 2$ rearrangement & $1(5 \%)$ & $77(19 \%)$ & 0.1456 & $0(0 \%)$ & $11(14 \%)$ & 1 & $1(6 \%)$ & $66(20 \%)$ & 0.3257 \\
\hline$B C L 6$ rearrangement & $1(6 \%)$ & $119(34 \%)$ & 0.026 & $0(0 \%)$ & $18(25 \%)$ & 0.5676 & $1(8 \%)$ & $101(36 \%)$ & 0.0628 \\
\hline$M Y C$ rearrangement & $2(11 \%)$ & $38(9 \%)$ & 0.6727 & $0(0 \%)$ & $8(10 \%)$ & 1 & $2(14 \%)$ & $30(8 \%)$ & 0.3571 \\
\hline *Double hit & $0(0 \%)$ & $16(4 \%)$ & 1 & $0(0 \%)$ & $3(4 \%)$ & 1 & $0(0 \%)$ & $13(4 \%)$ & 1 \\
\hline TP53 mutation & $2(10 \%)$ & $107(23 \%)$ & 0.2715 & $0(0 \%)$ & $18(20 \%)$ & 1 & $2(17 \%)$ & $89(23 \%)$ & 0.3805 \\
\hline
\end{tabular}

LDH; lactate dehydrogenase, ECOG; Eastern Cooperative Oncology Group, IPI; International Prognostic Index, EN; Extranodal ,CR; complete remission, PR; partial remission, GCB; germinal center B-cell-like phenotype, ABC; activated B-cell-like phenotype, pSTAT3; phosphorylated signal transducer and activator of transcription 3 .

*Double hit; MYC rearrangement with either BCL2 or BCL6 rearrangement

polymorphic lymphoproliferative disorder (LPD)-like features. It is characterized by a low density of neoplastic cells without HL-like features. In both age groups, EBV+ DLBCL patients did not show differences in their clinical parameters. Nineteen (58\%) cases had an ABC phenotype and $14(42 \%)$ cases had a GCB phenotype. Expression of LMP1 and EBNA2 was found 17 (68\%) and 5 (22\%) patients, respectively. Expression of CD30 (44\% vs. $14 \%, p<0.0001)$, p50 (61\% vs. 34\%, $p=0.0124)$ and phosphorylated signal transducer and activator of transcription 3 (pSTAT3) (39\% vs. 16\%, $p=0.0079)$ were more commonly observed than the EBV negative de novo DLBCL patients. BCL6 expression $(50 \%$ vs. $82 \%, p=$ $0.002)$ was less commonly observed in EBV+ DLBCL. Rearrangements of BCL2, BCL6 or MYC and TP53 mutation were infrequent in this study group.

\section{Effect of EBV infection in patients $\leq \mathbf{5 0}$ years of age}

Morphologic analysis showed the monomorphic variant in $3(18 \%)$ and the polymorphic variants in 13 $(82 \%)$ tumors (Figure 2$)$. In younger patients, EBV+ DLBCL did not show distinct clinicopathologic features compared with DLBCL without EBV infection in younger patients (Table 1). In younger patients with $\mathrm{EBV}+\mathrm{DLBCL}$, patients with an $\mathrm{ABC}(55 \%)$ phenotype was slightly more common than a GCB phenotype $(45 \%)(p=0.1793)$. Expression of LMP1 and EBNA2 was found $4(67 \%)$ and $2(40 \%)$ patients, respectively. BCL6 expression (38\%) was significantly lower in EBV+ DLBCL $(p=0.016)$. Expression of CD30 (43\%) and pSTAT3 (43\%) were more commonly observed, but did 
Table 2: Comparison between Epstein-Barr virus-positive diffuse large B-cell lymphoma patients age $\leq \mathbf{5 0}$ years and those age $>\mathbf{5 0}$ years

\begin{tabular}{|c|c|c|c|}
\hline & $\begin{array}{c}\text { Age } \leq 50 \text { years } \\
(n=16)\end{array}$ & $\begin{array}{c}\text { Age }>50 \text { years } \\
(n=30)\end{array}$ & $P$ value \\
\hline Median age, years (range) & $43(21-50)$ & $66(53-86)$ & $<0.0001$ \\
\hline Men:women & $7: 9$ & $18: 12$ & 0.3595 \\
\hline B symptoms & $7(47 \%)$ & $9(33 \%)$ & 0.5113 \\
\hline LDH elevation & $12(75 \%)$ & $19(68 \%)$ & 0.7385 \\
\hline Stage III/IV & $9(56 \%)$ & $19(66 \%)$ & 0.7488 \\
\hline ECOG $\geq 2$ & $2(13 \%)$ & $9(36 \%)$ & 0.1519 \\
\hline IPI $>2$ & $2(13 \%)$ & $14(52 \%)$ & 0.0203 \\
\hline$\geq 2$ EN involvement & $3(19 \%)$ & $6(21 \%)$ & 1 \\
\hline Size $\geq 6 \mathrm{~cm}$ & $5(38 \%)$ & $7(35 \%)$ & 1 \\
\hline CR/PR & $12(86 \%)$ & $27(90 \%)$ & 0.6467 \\
\hline GCB phenotype & $5(50 \%)$ & $9(41 \%)$ & 0.712 \\
\hline ABC phenotype & $5(50 \%)$ & $13(59 \%)$ & \\
\hline CD30 expression & $6(43 \%)$ & $10(45 \%)$ & 1 \\
\hline LMP1 expression & $4(66 \%)$ & $13(68 \%)$ & 1 \\
\hline EBNA2 expression & $2(40 \%)$ & $3(17 \%)$ & 0.2907 \\
\hline p50 expression & $3(43 \%)$ & $11(69 \%)$ & 0.363 \\
\hline p65 expression & $0(0 \%)$ & $3(15 \%)$ & 0.5453 \\
\hline cREL expression & $1(14 \%)$ & $4(27 \%)$ & 1 \\
\hline pSTAT3 expression & $3(43 \%)$ & $6(38 \%)$ & 1 \\
\hline BCL2 expression & $3(38 \%)$ & $9(43 \%)$ & 1 \\
\hline BCL6 expression & $3(38 \%)$ & $11(52 \%)$ & 1 \\
\hline p53 expression & $2(29 \%)$ & $8(39 \%)$ & 0.6214 \\
\hline MYC expression & $3(43 \%)$ & $14(67 \%)$ & 0.3809 \\
\hline MYC/BCL2 expression & $1(14 \%)$ & $7(33 \%)$ & 0.6334 \\
\hline$B C L 2$ rearrangement & $0(0 \%)$ & $1(6 \%)$ & 1 \\
\hline$B C L 6$ rearrangement & $0(0 \%)$ & $1(8 \%)$ & 1 \\
\hline$M Y C$ rearrangement & $0(0 \%)$ & $2(14 \%)$ & 1 \\
\hline *Double hit & $0(0 \%)$ & $0(0 \%)$ & $\mathrm{N} / \mathrm{A}$ \\
\hline TP53 mutation & $0(0 \%)$ & $2(17 \%)$ & 1 \\
\hline
\end{tabular}

LDH; lactate dehydrogenase, ECOG; Eastern Cooperative Oncology Group, IPI; International Prognostic Index, EN; Extranodal ,CR; complete remission, PR; partial remission, GCB; germinal center B-cell-like phenotype, ABC; activated B-cell-like phenotype, pSTAT3; phosphorylated signal transducer and activator of transcription 3, N/A; not available.

*Double hit; $M Y C$ rearrangement with either BCL2 or BCL6 rearrangement 
Table 3: Expression of microRNAs in patients with Epstein-Barr virus-positive diffuse large B-cell lymphoma who are $\leq \mathbf{5 0}$ years and $>50$ years old

\begin{tabular}{lccc}
\hline & $\begin{array}{c}\text { S50 years } \\
\text { Median* (range) }\end{array}$ & $\begin{array}{c}>\mathbf{5 0} \text { years } \\
\text { Median* (range) }\end{array}$ & P value** \\
\hline miR-126-3p & $1193(1157$ to 1228$)$ & $631(311$ to 2102$)$ & 0.5252 \\
miR-146a-5p & $1109(554$ to 1664$)$ & $617(297$ to 2709$)$ & 0.9625 \\
miR-146b-5p & $280(170$ to 390$)$ & $247(118$ to 1221$)$ & 0.7113 \\
miR-150-5p & $2223(2138$ to 2308$)$ & $877(352$ to 3576$)$ & 0.2648 \\
miR-222-3p & $448(371$ to 525$)$ & $458(151$ to 1782$)$ & 0.7831 \\
\hline
\end{tabular}

* Number indicates the number of detected probes

** Unpaired t-test, two-sided

A

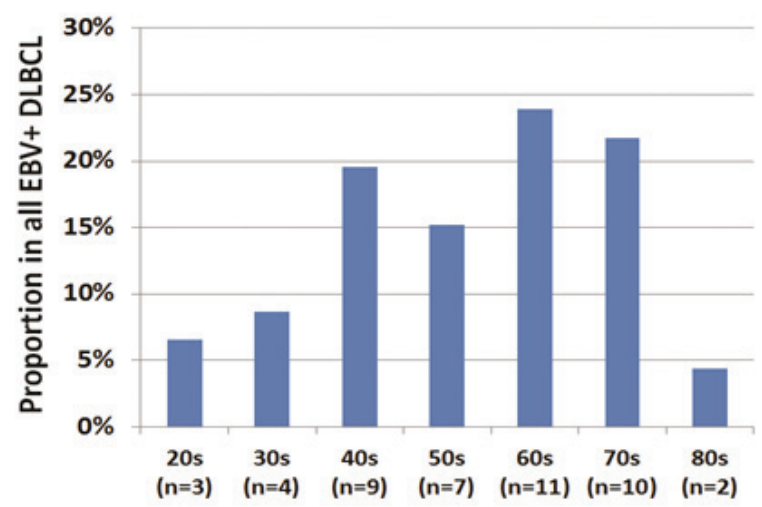

Number of patients in each age group

B

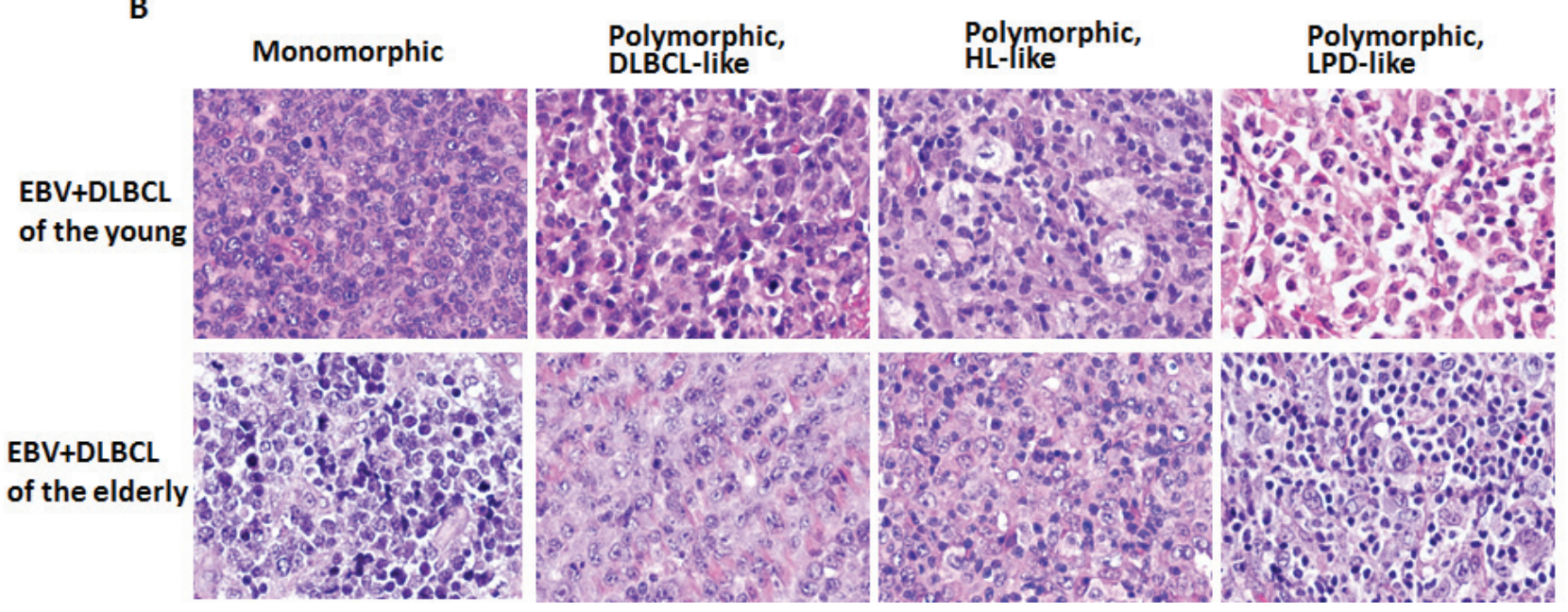

Figure 1: Distribution and morphologic variants of EBV+ DLBCL patients in each age group. A. Distribution of EBV+ DLBCL patients in each age group. B. Morphologic variants in EBV-positive diffuse large B-cell lymphoma of the young (upper panel) and elderly (lower panel). Similar variants are seen in both groups of patients. The monomorphic subtype is featured by monotonous sheets of large transformed B cells. The polymorphic DLBCL-like subtype shows canonical large B-cell neoplasm morphology, with a high density of large neoplastic cells and scattered cells with (Reed-Sternberg) RS-like and Hodgkin-like features. The polymorphic HL-like subtype displays a lower density of neoplastic cells with RS-like and Hodgkin-like features. The polymorphic LPD-like subtype is a DLBCL with polymorphic lymphoproliferative disorder (LPD)-like features. It is characterized by a low density of neoplastic cells without HL-like features. 
not achieve statistical significance $(p=0.0727$ and $p=$ 0.0818 , respectively). There was no significant difference in expression of other markers. Rearrangements in BCL2, BCL6 and MYC and TP53 mutation were infrequently detected in patients $<50$ years with EBV+ DLBCL.

\section{Effect of EBV infection in patients $>50$ years of age}

In older patients, monomorphic and polymorphic variants represented $5(17 \%)$ and $25(83 \%)$ of cases, respectively (Figure 3 ). Performance status (ECOG $\geq 2$ ) was worse in the older age group (Table 1). There were no significant differences in other clinical features between EBV+ and EBV- DLBCL. The ABC phenotype occurred in $18(59 \%)$ and the GCB phenotype in $12(41 \%)$ tumors. Expression of LMP1 and EBNA2 was found 13 (68\%) and $3(17 \%)$ patients, respectively. Expression of CD30 (48\%), NF-кB p50 (69\%) and pSTAT3 (38\%) were more commonly observed in EBV+ DLBCL $(p=0.0003, p$ $=0.0056$ and $p=0.0389$, respectively). Expression of BCL6 (52\%) was less frequent in EBV+ DLBCL in older patients $(p=0.0024)$. There was no significant difference in expression of other markers. Rearrangements in BCL2, BCL6 and MYC and TP53 mutation were uncommon in $\mathrm{EBV}+\mathrm{DLBCL}$.

\section{$\mathrm{EBV}+\mathrm{DLBCL}$ in patients $\leq \mathbf{5 0}$ years $v s .>\mathbf{5 0}$ years old}

We also compared the clinicopathologic, immunophenotypic, and genetic features of EBV+ DLBCL in younger ( $\leq 50$ years) versus older ( $>50$ years) patients (Table 2). Significant differences were not observed

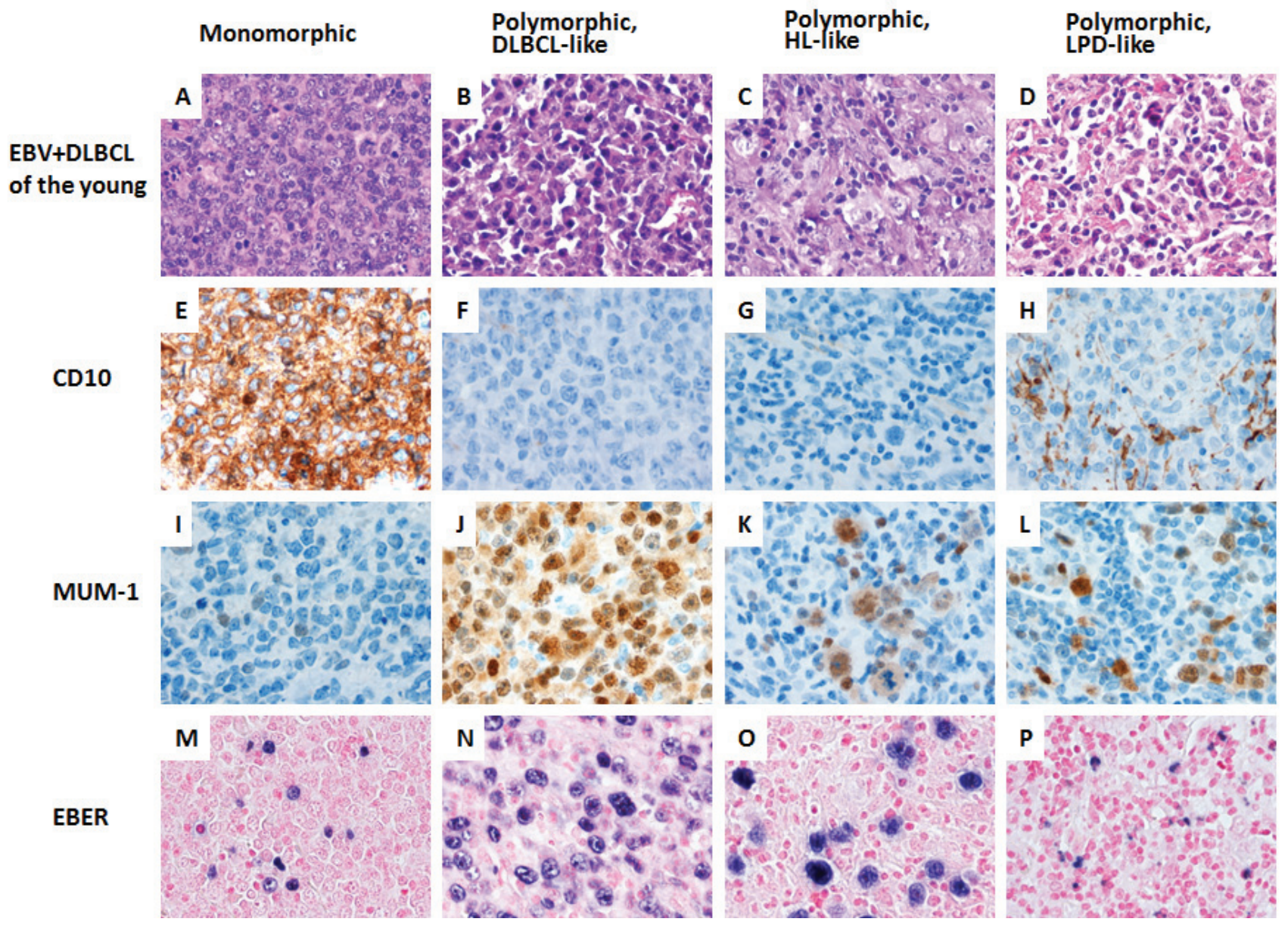

Figure 2: A spectrum of morphologic variants and immunophenotypic profiling in EBV-positive diffuse large B-cell lymphoma of the younger patients. A. E. I. M., The monomorphic case presented in this figure shows the GCB subtype. All polymorphic subtypes show the ABC-DLBCL molecular phenotype. B. F. J. N., Polymorphic DLBCL-like variant shows canonical large B-cell neoplasm morphology. C. G. K. O., The polymorphic HL-like variant shows Hodgkin lymphoma-like features. D. H. L. P., The polymorphic LPD-like variant shows polymorphic lymphoproliferative disorder (LPD)-like features with a low density of neoplastic cells without HL-like features. All images are shown at a magnification of x 600 . 


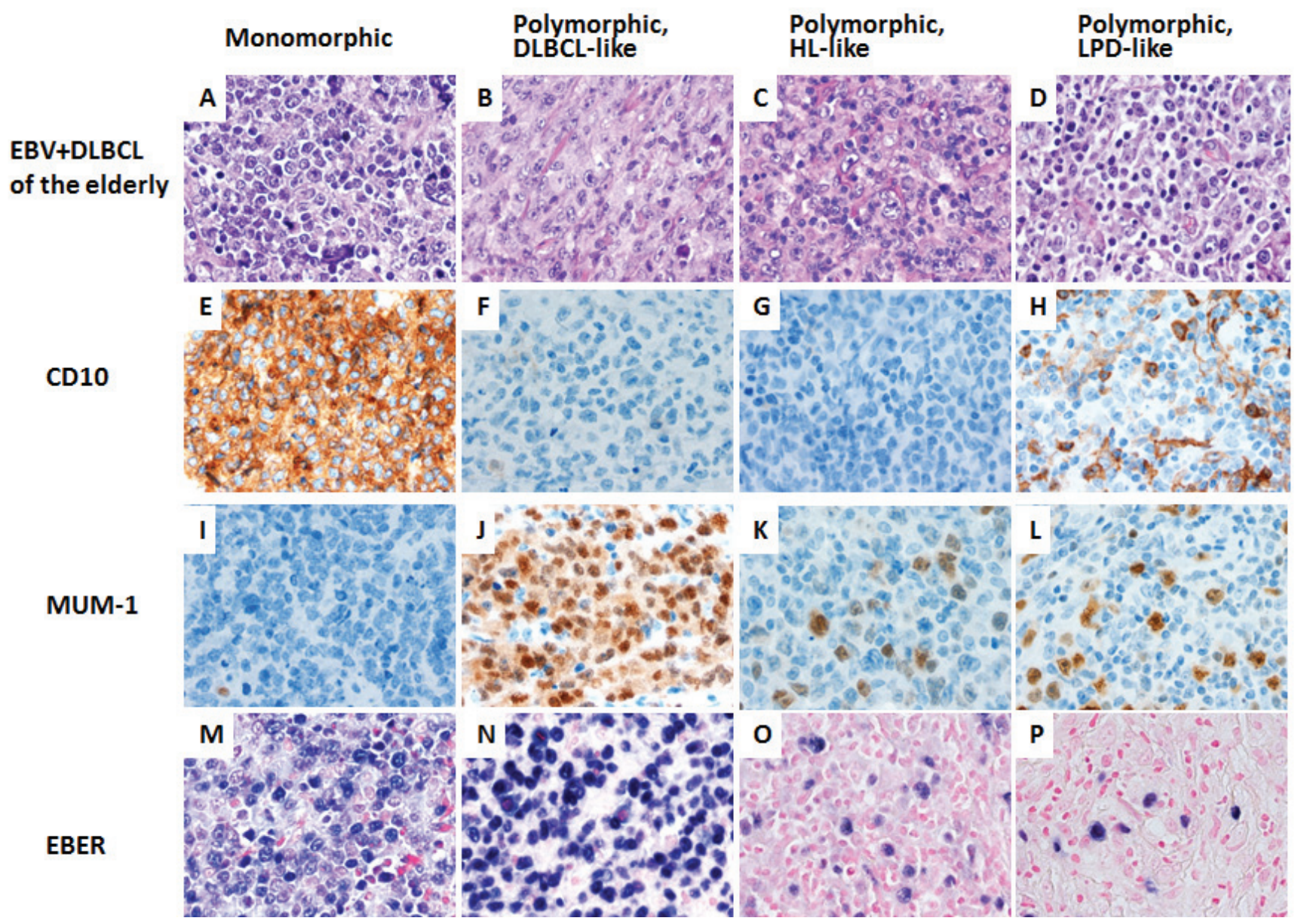

Figure 3: A spectrum of morphologic variants and immunophenotypic profiling in EBV-positive diffuse large B-cell lymphoma of the elderly patients. A. E. I. M., The monomorphic case presented in this figure shows the GCB subtype. All polymorphic subtypes show the ABC-DLBCL molecular phenotype. B. F. J. N., Polymorphic DLBCL-like variant shows canonical large B-cell neoplasm morphology. C. G. K. O., The polymorphic HL-like variant shows Hodgkin lymphoma-like features. D. H. L. P., The polymorphic PLPD-like variant shows polymorphic lymphoproliferative disorder (LPD)-like features with a low density of neoplastic cells without HL-like features. All images are shown at a magnification of x 600 .

A

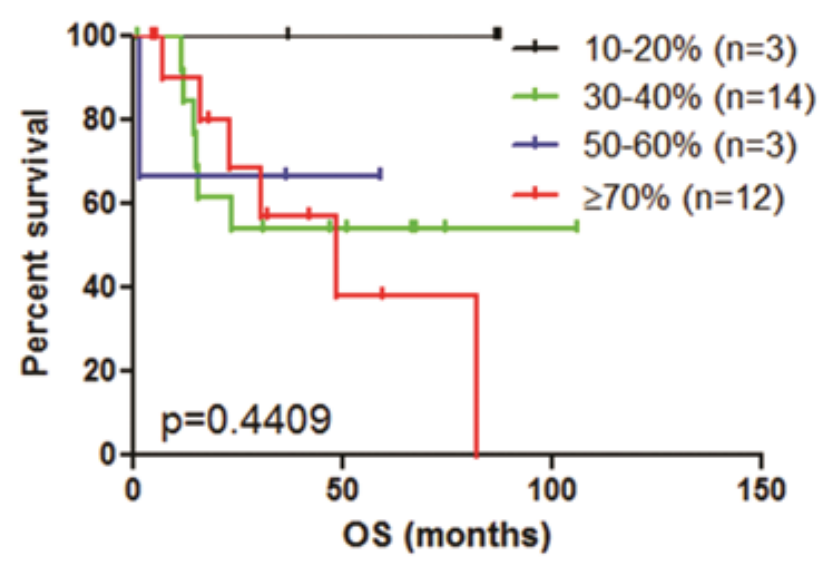

B EBER and survival

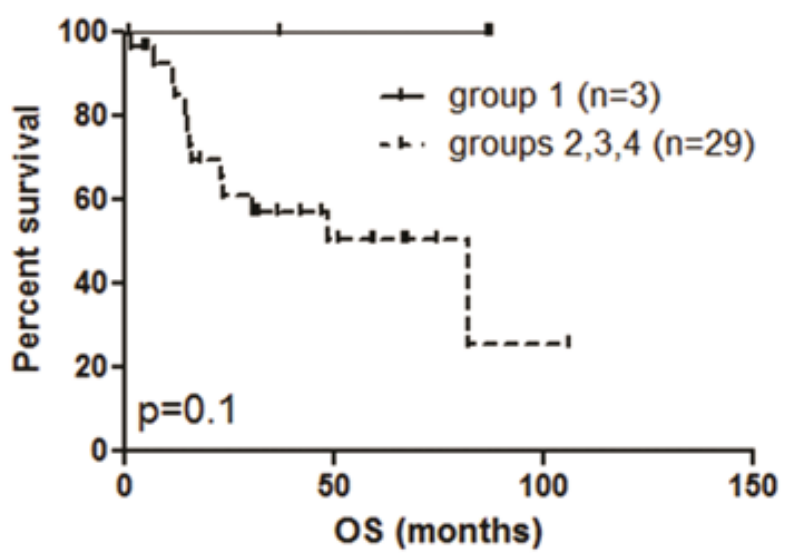

Figure 4: Survival analysis of variable EBER expression impact on survival. A. Survival analysis of four groups did not show significant difference in survival ( $p=0.4409)$ if EBER expression is calculated for group 1 (10-20\%), group $2(30-40 \%)$, group $3(50-60 \%)$ and group $4(\geq 70 \%)$. B., We merged groups 2,3 and 4 and compared with group 1, but did not show significant difference in overall survival $(p=0.1)(\mathrm{B})$. 

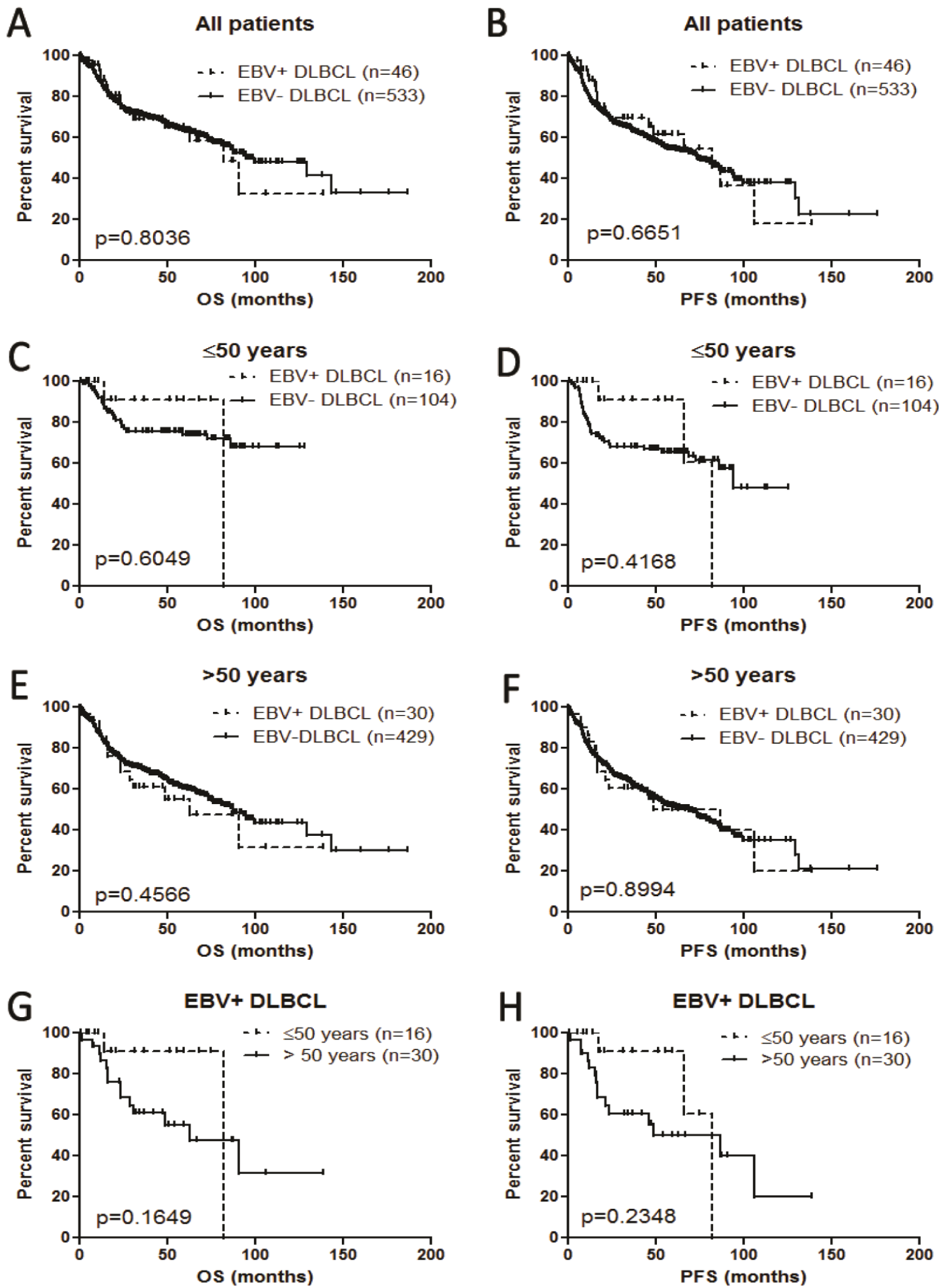

Figure 5: Survival analysis of EBV+ diffuse large B-cell lymphoma in all the patients and different age groups. A. and B. Overall survival (OS) and progression-free survival (PFS) in all patients. C. and D. OS and PFS in patients $\leq 50$ years. E. and F. OS and PFS in patients $>50$ years. G. and $\mathbf{H}$. OS and PFS in patients with EBV+ DLBCL. 
in other clinical features, protein expression profile or genetic features between younger and older patients with EBV+ DLBCL. We performed gene expression profiling in 5 younger and 20 older patients with EBV+ DLBCL and there was no significant differences in gene expression between the two groups. We also compared the expression of hsa-miR-126, hsa-miR-146a, hsa-miR-146b, hsa-miR-150 and hsa-miR-222 in 2 younger and 7 older patients with EBV+ DLBCL and there were no significant differences in expression of these microRNAs between the two groups (Table 3 ).

\section{Impact on survival}

We first examined if variation in EBER expression dictates significant impact on survival. We created four groups based on EBER expression; group 1 (10-20\%), group $2(30-40 \%)$, group $3(50-60 \%)$ and group $4(\geq 70 \%)$. Survival analysis of these groups did not show significant difference in survival ( $p=0.4409)$. (Figure 4A). Although not statistically powered, group 1 appeared to stand out from the remaining groups. We merged groups 2, 3 and 4 and compared with group 1 , but did not show significant difference in overall survival ( $p=0.1$ ) (Figure 4B).

In all age groups, EBV+ DLBCL versus EBVDLBCL showed no difference in overall survival (OS) nor progression-free survival (PFS) (Figure 5A and 5B). Separating younger and older patients, EBV+ DLBCL did not show poorer outcome compared with younger and older patients with EBV- DLBCL (Figures 5C, 5D, $5 \mathrm{E}$ and $5 \mathrm{~F})$. In the group of patients with $\mathrm{EBV}+\mathrm{DLBCL}$, younger ( $\leq 50$ years) and older ( $>50$ years) did not show significant differences in OS and PFS (Figure 5G and 5H).

Our group previously identified that EBV+ DLBCL with co-expression of CD30 harbor extremely poor survival [5]. In all age groups, EBV+ DLBCL with coexpression of CD30 had significantly poor overall survival compared with EBV+ DLBCL without CD30 expression $(p=0.0382)$. Separating younger and older patients, however, CD30 co-expression was not statistically powered in overall survival in both groups $(p=0.1573$ and $p=0.1911$, respectively).

In all age groups, univariate analysis showed that an increased hazard was observed for the presence of $B$ symptoms, elevated serum LDH, advanced (III/IV) stage, involvement of $\geq 2$ extranodal sites, ECOG $\geq 2$, IPI $\geq 3$, size $\geq 6 \mathrm{~cm}$ and ABC subtype. However, EBV was not associated with increased hazard. Separating younger and older age groups, EBV did not portend increased risk in both groups by univariate analysis. Multivariate analysis was not performed for EBV because univariate analysis was insignificant.

\section{DISCUSSION}

$\mathrm{EBV}+\mathrm{DLBCL}-\mathrm{e}$ is a provisional entity in the current WHO classification. The notion that DLBCL associated with EBV could harbor a worse outcome has been generally accepted among pathologists and oncologists, but for the age cutoff of 50 years there has been some degree of resistance in the community. The resistance is partly due to the fact the age of 50 years seems arbitrary. $\mathrm{EBV}+\mathrm{DLBCL}$ has been documented in patients younger than 50 years of age and the 50 year cutoff seems too young to be designated as "elderly". Although the age cutoff appears somewhat arbitrary, the data of Oyama and colleagues might provide a possible rationale. In their study, there was a stark difference with respect to the incidence of EBV+ lymphoproliferative disorder in patients without predisposing immunodeficiency in < 50 years $(6 \%)$ and $\geq 50$ years (94\%) [10]. However, our cohort does not reproduce the difference (35\% vs. $65 \%$, respectively). Instead, there were more patients in the fifth as compared with the sixth decade. The discrepancy between the data of Oyama and colleagues versus the patients group currently presented could be attributable to different ethnic group.

Regardless of age, we did not observe distinct clinical manifestations between patients with EBV+ DLBCL compared with DLBCL without EBV infection. Our data is in contrast with a report from Korea, in which advanced (III/IV) stage, $\geq 2$ extranodal sites of involvement, and high intermediate/high IPI were more common in patients who were $>50$ years [12]. The difference also could be attributable to different ethnicities (Korean vs. Caucasian). In an earlier study, we showed that $\mathrm{EBV}+\mathrm{DLBCL}$ in Caucasian patients is distinct from Asian patients [5]. By immunohistochemistry, expression of CD30, NF- $\kappa \mathrm{B}$ p50, pSTAT3 were more frequent and BCL6 expression was less commonly seen in EBV+ DLBCL. Rearrangements of BCL2, BCL6 or $M Y C$ and TP53 mutation were uncommon. These results are consistent with previously published data [5]. In the younger ( $\leq 50$ years) group, EBV+ DLBCL did not show distinct clinical, immunophenotypic and genetic features except less frequent expression of BCL6. Regarding expression of CD30 and pSTAT3, only trends were observed ( $p=0.0727$ and $p=0.0818$, respectively). We believe these results might be due to the relatively low number $(n=16)$ of patients in younger age group because these proteins are more commonly expressed in older age group.

Comparing younger and older patients with EBV+ DLBCL, significant differences were found in median age (43 vs. 66 years) and the proportion of patients with IPI $>2(13 \%$ vs. 52\%). The difference in median age is expected because the comparison was based on age. The 
IPI score is based on age, stage, serum LDH, ECOG score and number of extranodal sites [14]. Excluding age from the score, $22 \%$ of the older patients retained an IPI $>2$. The remaining clinical, immunophenotypic, including LMP1 and EBNA2, and genetic features were not different between the two groups. Furthermore, gene expression profiling did not show distinctive features between younger and older group, consistent with data published by others [12]. In a recent study, EBV+ DLBCL in patients aged $>50$ years showed overexpression of hsamiR-126, hsa-miR-146a, hsa-miR-146b, hsa-miR-150 and hsa-miR-222 compared to EBV- DLBCL in the same age group [15]. We compared the expression of these microRNAs in younger versus older patients with EBV+ DLBCL and did not observe any significant differences.

In an earlier report, we showed that EBV infection in DLBCL does not impact survival in Caucasian patients. In this expanded cohort, we reproduced the same result. Separating the younger and older groups, EBV infection in DLBCL also did not correlate with shorter survival in either group. For patients with EBV+ DLBCL, younger and older patients had a similar outcome.

$\mathrm{EBV}+\mathrm{DLBCL}$ with CD30 co-expression has extremely poor survival [5] and we reproduced the result in the current study. Considering frequent expression of CD30 in EBV+ DLBCL and availability of brentuximab vedotin, targeting CD30 could be an attractive therapeutic option for patients with EBV+ DLBCL [22].

In summary, about one third of patients with $\mathrm{EBV}+\mathrm{DLBCL}$ are younger than 50 years of age and this subgroup has similar clinicopathologic, immunophenotypic features and survival compared with patients who are $>50$ years. We also show that the gene expression profiling and microRNA profiles of younger patients with EBV+ DLBCL is similar to older patients. Based on the data present, we suggest that arbitrary age cutoff for EBV + DLBCL proposed in the WHO classification is unnecessary.

\section{MATERIALS AND METHODS}

\section{Patient selection}

Since our previous report of 28 cases [5], 11 more cases of $\mathrm{EBV}+\mathrm{DLBCL}$ were added to the International DLBCL Rituximab-CHOP Consortium Program Study. All cases were reviewed by a group of hematopathologists and were diagnosed according to the WHO criteria. We also identified 7 cases of EBV+ DLBCL by searching the archives of The University of Texas MD Anderson Cancer Center. We classified morphologic variants of $\mathrm{EBV}+\mathrm{DLBCL}$ based on the description of Monte-Moreno and colleagues [16]. To compare clinicopathologic and genetic features, cohorts of de novo DLBCL in patients $\leq 50$ years old $(n=104)$ and $>50$ years old $(n=429)$ were selected from the Consortium Study. Exclusion criteria included DLBCL transformation from a low-grade B-cell lymphoma, association of immunodeficiency (e.g., HIV infection or common variable immunodeficiency), primary cutaneous DLBCLs, primary central nervous system DLBCLs, and primary mediastinal large B-cell lymphomas. This study was conducted in accord with the Declaration of Helsinki and was approved by the Institutional Review Boards (IRB) of all participating collaborative institutions. The overall study was approved by the IRB at The University of Texas MD Anderson Cancer Center.

\section{Immunohistochemistry and in situ hybridization methods}

Hematoxylin and eosin stained slides from each case were reviewed and tumor-rich areas were selected. Tissue microarrays (TMA) were constructed using a tissue microarrayer (Beecher Instrument, Silver Spring, MD). Immunohistochemical analysis was performed on 4- $\mu \mathrm{m}$ TMA sections using a streptavidin-biotin complex technique with antibodies reactive with the following antigens: BCL2, BCL6, CD10, CD30, EBNA2, FOXP-1, GCET1, IRF4/MUM-1, LMP1, MYC, NF-kB p50, p65 and c-Rel, pSTAT3, and p53. In situ hybridization (ISH) for EBV-encoded RNA (EBER) was performed. Due to tissue exhaustion, staining was not always available for each marker. Antigen expression was scored in $10 \%$ increments by assessing the percentage of immunoreactive tumor cells. Receiver-operating characteristic (ROC) curve analyses and X-tile analyses were used to determine a prognostically relevant cutoff with optimal sensitivity and specificity for each marker [17]. When an optimal cutoff value for an individual marker could not be determined by ROC curve, a conventional cutoff value was decided based on reports in the literature. The cutoff scores for these markers used in this study were as follows: $10 \%$ for EBER, EBNA2 and LMP1; 20\% for CD30, p50 and p53; $30 \%$ for CD10, BCL6 and c-Rel; 40\% for MYC and p65; $50 \%$ for pSTAT3; $60 \%$ for GCET1, MUM-1 and FOXP1; and $70 \%$ for BCL2.

\section{Fluorescence in situ hybridization (FISH)}

FISH analysis was performed on formalin-fixed, paraffin embedded tissue sections using BCL2 and BCL6 dual-color break-apart probes (Vysis), MYC locusspecific $I G H / M Y C / C E P 8$ tricolor dual-fusion probes, and a locus-specific MYC dual-color break-apart probe 
(Vysis) as described previously [18]. TP53 sequencing was performed using extracted genomic DNA from formalin-fixed, paraffin-embedded tissue in the training set. The coding sequence (exons 2-11) and splicing sites were sequenced using p53 AmpliChip (Roche Molecular Systems) as described previously [19]. For data analysis, the TP53 reference sequence (NC_000017.10) in the GenBank database was used.

\section{Gene expression profiling}

Total RNA was extracted from 25 formalin-fixed, paraffin-embedded (FFPE) tissue blocks using the High Pure RNA Extraction Kit (Roche Applied Science) and subjected to gene expression profiling (GEP) as has been described [20]. For data analysis and classification, we used the DQN algorithm, which is the noncentral trimmed mean of differences between perfect match and mismatch intensities with quantile normalization [21]. DQN was normalized with beta distribution and a Bayesian model was used to determine the classification probability.

\section{Cell-of-origin (COO) classification}

Cell-of-origin classification was achieved by combining GEP (considered the "gold standard") and IHC data as described previously [20]. In a total of 41 cases COO was determined, by GEP with 25 cases and by IHC in 8 cases, respectively.

\section{EBV+ DLBCL microRNA profiling}

The HTG EdgeSeq Whole Transcriptome Assay coupled with the Illumina HiSeq was used for measuring expression of hsa-miR-126, hsa-miR-146a, hsa-miR146b, hsa-miR-150 and hsa-miR-222 from FFPE tissue blocks. A total of 9 patients were tested including 2 younger $(\leq 50$ years $)$ and 7 older $(>50$ years $)$ patients with EBV+ DLBCL. Selection of 5 microRNAs was based on previously published data.[15]

\section{Statistical analysis}

Clinical and laboratory features were compared with the Fisher exact test for categorical variables and Mann-Whitney U test or unpaired t-test if for continuous variables. Overall survival (OS) and progression-free survival (PFS) were defined from the date of diagnosis to the date of last follow-up or death and from the date of diagnosis to the date of progression or death, respectively. Survival distributions were estimated with the KaplanMeier method, with difference compared by the log- rank test. Univariate analysis was performed using the Cox proportional hazards regression model. Two-sided $p<0.05$ was considered to be statistically significant. GraphPad Prism V5 (La Jolla, CA) and SPSS Statistics V21 (Armonk, NY) were used for statistical analyses.

\section{ACKNOWLEDGMENTS}

This study is supported by the National Cancer Institute and National Institutes of Health grants (R01CA138688 and R01CA187415, K.H.Y). CYO is the recipient of the advanced molecular pathology fellowship and hematopathology research awards; ZYXM is the recipient of the Harold C. and Mary L. Daily Endowment Fellowships and Shannon Timmins Fellowship for Leukemia Research Award. GM is supported by a grant from the Michael and Susan Dell Foundation. KHY is supported by The University of Texas MD Anderson Cancer Center Institutional Research Grant Award, an MD Anderson Lymphoma Specialized Programs of Research Excellence (SPORE) Research Development Program Award, an MD Anderson Myeloma SPORE Research Development Program Award, MD Anderson Collaborative Research Funds with High-Throughput Molecular Diagnostics, Gilead Pharmaceutical, Adaptive Biotechnology, and Roche Molecular Systems. This work was also partially supported by National Cancer Institute and National Institutes of Health grants (P50CA136411 and P50CA142509), and by the MD Anderson Cancer Center Support Grant CA016672.

\section{CONFLICTS OF INTERESTS}

No conflict of interest from all participating authors

\section{REFERENCES}

1. Nakamura S, Jaffe ES and Swerdlow SH. (2008). EBV positive diffuse large B-cell lymphoma of the elderly. In: Swerdlow SH, Campo E, Harris NL, Jaffe ES, Pileri SA, Stein H, Thiele J and Vardiman JW, eds. WHO Classification of Tumours of Haematopoietic and Lymphoid Tissues. (Lyon: International Agency for Research on Cancer), pp. 243-244.

2. Park S, Lee J, Ko YH, Han A, Jun HJ, Lee SC, Hwang IG, Park YH, Ahn JS, Jung CW, Kim K, Ahn YC, Kang WK, Park K and Kim WS. The impact of Epstein-Barr virus status on clinical outcome in diffuse large B-cell lymphoma. Blood. 2007; 110:972-978.

3. Kuze T, Nakamura N, Hashimoto Y, Sasaki Y and Abe M. The characteristics of Epstein-Barr virus (EBV)-positive diffuse large B-cell lymphoma: comparison between $\operatorname{EBV}(+)$ and $\operatorname{EBV}(-)$ cases in Japanese population. Jpn J 
Cancer Res. 2000; 91:1233-1240.

4. Hofscheier A, Ponciano A, Bonzheim I, Adam P, LomeMaldonado C, Vela T, Cortes E, Ortiz-Hidalgo C, Fend F and Quintanilla-Martinez L. Geographic variation in the prevalence of Epstein-Barr virus-positive diffuse large B-cell lymphoma of the elderly: a comparative analysis of a Mexican and a German population. Mod Pathol. 2011; 24:1046-1054.

5. Ok CY, Li L, Xu-Monette ZY, Visco C, Tzankov A, Manyam GC, Montes-Moreno S, Dybkaer K, Chiu A, Orazi A, Zu Y, Bhagat G, Chen J, Richards KL, Hsi ED, Choi WW, et al. Prevalence and clinical implications of epstein-barr virus infection in de novo diffuse large B-cell lymphoma in Western countries. Clin Cancer Res. 2014; 20:2338-2349.

6. Ok CY, Papathomas TG, Medeiros LJ and Young KH. EBV-positive diffuse large B-cell lymphoma of the elderly. Blood. 2013; 122:328-340.

7. Perepu U, Dogan A, Maurer M, Allmer C, Thompson C, Ansell S, Syrbu SI, Slager S, Witzig T, Weiner G, Habermann T, Cerhan J and Link B. EBV $(+)$ Diffuse Large B Cell Lymphoma Is Infrequent in Upper Central United States and Lacks Unique Clinical Characteristics or Adverse Prognosis Compared to EBV (-) Counterparts: Results From University of Iowa/Mayo Clinic SPORE. 2012 ASH Meeting Abstract. 2012; \#1604.

8. Sato A, Nakamura N, Kojima M, Ohmachi K, Carreras J, Kikuti YY, Numata H, Ohgiya D, Tazume K, Amaki J, Moriuchi M, Miyamoto M, Aoyama Y, Kawai H, Ichiki A, Hara R, et al. Clinical outcome of Epstein-Barr viruspositive diffuse large B-cell lymphoma of the elderly in the rituximab era. Cancer Sci. 2014; 105:1170-1175.

9. Ahn JS, Yang DH, Duk Choi Y, Jung SH, Yhim HY, Kwak JY, Sung Park H, Shin MG, Kim YK, Kim HJ and Lee JJ. Clinical outcome of elderly patients with Epstein-Barr virus positive diffuse large B-cell lymphoma treated with a combination of rituximab and CHOP chemotherapy. Am J Hematol. 2013; 88:774-779.

10. Oyama T, Yamamoto K, Asano N, Oshiro A, Suzuki R, Kagami Y, Morishima Y, Takeuchi K, Izumo T, Mori S, Ohshima K, Suzumiya J, Nakamura N, Abe M, Ichimura K, Sato Y, et al. Age-related EBV-associated B-cell lymphoproliferative disorders constitute a distinct clinicopathologic group: a study of 96 patients. Clin Cancer Res. 2007; 13:5124-5132.

11. Beltran BE, Morales D, Quinones P, Medeiros LJ, Miranda $\mathrm{RN}$ and Castillo JJ. EBV-positive diffuse large b-cell lymphoma in young immunocompetent individuals. Clin Lymphoma Myeloma Leuk. 2011; 11:512-516.

12. Hong JY, Yoon DH, Suh C, Huh J, Do IG, Sohn I, Jo J, Jung SH, Hong ME, Yoon H, Ko YH, Kim SJ and Kim WS. EBV-positive diffuse large B-cell lymphoma in young adults: is this a distinct disease entity? Ann Oncol. 2015;
26:548-555.

13. Uccini S, Al-Jadiry MF, Scarpino S, Ferraro D, Alsaadawi AR, Al-Darraji AF, Moleti ML, Testi AM, Al-Hadad SA and Ruco L. Epstein-Barr virus-positive diffuse large B-cell lymphoma in children: a disease reminiscent of EpsteinBarr virus-positive diffuse large B-cell lymphoma of the elderly. Hum Pathol. 2015.

14. A predictive model for aggressive non-Hodgkin's lymphoma. The International Non-Hodgkin's Lymphoma Prognostic Factors Project. N Engl J Med. 1993; 329(:987994.

15. Andrade TA, Evangelista AF, Campos AH, Poles WA, Borges NM, Camillo CM, Soares FA, Vassallo J, Paes RP, Zerbini MC, Scapulatempo C, Alves AC, Young KH and Colleoni GW. A microRNA signature profile in EBV+ diffuse large B-cell lymphoma of the elderly. Oncotarget. 2014; 5:11813-11826.

16. Montes-Moreno S, Odqvist L, Diaz-Perez JA, Lopez AB, de Villambrosia SG, Mazorra F, Castillo ME, Lopez M, Pajares R, Garcia JF, Mollejo M, Camacho FI, RuizMarcellan C, Adrados M, Ortiz N, Franco R, et al. EBVpositive diffuse large B-cell lymphoma of the elderly is an aggressive post-germinal center B-cell neoplasm characterized by prominent nuclear factor- $\mathrm{kB}$ activation. Mod Pathol. 2012; 25:968-982.

17. Ok CY, Xu-Monette ZY, Tzankov A, O’Malley DP, Montes-Moreno S, Visco C, Moller MB, Dybkaer K, Orazi A, Zu Y, Bhagat G, Richards KL, Hsi ED, Han van Krieken J, Ponzoni M, Farnen JP, et al. Prevalence and clinical implications of cyclin D1 expression in diffuse large B-cell lymphoma (DLBCL) treated with immunochemotherapy: a report from the International DLBCL Rituximab-CHOP Consortium Program. Cancer. 2014; 120:1818-1829.

18. Tzankov A, Xu-Monette ZY, Gerhard M, Visco C, Dirnhofer S, Gisin N, Dybkaer K, Orazi A, Bhagat G, Richards KL, Hsi ED, Choi WW, van Krieken JH, Ponzoni M, Ferreri AJ, Ye Q, et al. Rearrangements of MYC gene facilitate risk stratification in diffuse large B-cell lymphoma patients treated with rituximab-CHOP. Mod Pathol. 2014; 27:958-971.

19. Xu-Monette ZY, Wu L, Visco C, Tai YC, Tzankov A, Liu WM, Montes-Moreno S, Dybkaer K, Chiu A, Orazi A, Zu Y, Bhagat G, Richards KL, Hsi ED, Zhao XF, Choi WW, et al. Mutational profile and prognostic significance of TP53 in diffuse large B-cell lymphoma patients treated with R-CHOP: report from an International DLBCL RituximabCHOP Consortium Program Study. Blood. 2012; 120:39863996.

20. Visco C, Li Y, Xu-Monette ZY, Miranda RN, Green TM, Tzankov A, Wen W, Liu WM, Kahl BS, d'Amore ES, Montes-Moreno S, Dybkaer K, Chiu A, Tam W, Orazi $\mathrm{A}, \mathrm{Zu} \mathrm{Y}$, et al. Comprehensive gene expression profiling and immunohistochemical studies support application 
of immunophenotypic algorithm for molecular subtype classification in diffuse large B-cell lymphoma: a report from the International DLBCL Rituximab-CHOP Consortium Program Study. Leukemia. 2012; 26:21032113.

21. Liu WM, Li R, Sun JZ, Wang J, Tsai J, Wen W, Kohlmann $A$ and Williams PM. PQN and DQN: algorithms for expression microarrays. J Theor Biol. 2006; 243:273-278.

22. Young KH, Medeiros LJ, Chan WC: Diffuse large B-cell lymphoma. In: Orazi A, Weiss LM, Foucar K, Knowles DM, eds. Neoplastic Hematopathology. Philadelphia, PA, USA. . Lippincott Willaims \& Wilkins; 2014:502-565. 